\title{
Experimental Assessment of Specific Absorption Rate Using Measured Electric Field Strength in Benson Idahosa University and Environs
}

\author{
Isabona Joseph ${ }^{1,}$,, Ojuh Osamiromwen Divine ${ }^{2}$ \\ ${ }^{1}$ Department of Physics, Federal University Lokoja, Lokoja, Kogi State, Nigeria \\ ${ }^{2}$ Department of Basic Sciences Benson Idahosa University, Benin City, Nigeria
}

Email address:

jisabona@biu.edu.ng (I. Joseph), dojuh@bui.edu.ng(O. O. Divine)

\section{To cite this article:}

Isabona Joseph, Ojuh Osamiromwen Divine. Experimental Assessment of Specific Absorption Rate Using Measured Electric Field Strength in Benson Idahosa University and Environs. American Journal of Modern Physics. Vol. 4, No. 2, 2015, pp. 92-96.

doi: 10.11648/j.ajmp.20150402.16

\begin{abstract}
There has been growing concern in Nigeria and even the world at large that exposure to radiation from base stations and mobile handsets could lead to increased risk of illnesses such as cancer and may adversely affect cognitive functions like concentration and may cause memory loss, headaches, dizziness and epilepsy among others. In the present paper, the Assessment of RF radiation in the far-field from selected mobile base station sites in BIU and environs, Benin City, Nigeria has been carried out using a handheld three-axis radio frequency meter (EMF meter) for measurement of Electric field. The meter is a broad band device for monitoring high frequency radiation in range of $50 \mathrm{MHz}$ to $3.6 \mathrm{GHz}$. It is used in three-axis (isotropic) measurement mode. The electric field strength of RF radiation within a radial distance of the range $0-100 \mathrm{~m}$ was measured with the RF meter. The average values of the Specific absorption rate (SAR) for the general public was estimated from the measured electric field strength and the values gotten were compared with International commission on Non-ionizing radiation. Results shows that the values of the SAR for the eighth base stations selected for the study are within the range of $0.00010 \mathrm{~W} / \mathrm{Kg}-0.0012 \mathrm{~W} / \mathrm{Kg}$. These values are quite lower than the limit by International Commission on Non -ionizing Radiation Protection (ICNIRP) which is $0.08 \mathrm{~W} / \mathrm{Kg}$ for the whole body average SAR. This may indicate that there is no significant health risk for the general public that are always the vicinity of the Far field of the selected base stations for the various mobile service provider the area.
\end{abstract}

Keywords: Mobile Phone Base Station, International Commission on Non-Ionizing Radiation Protection, Specific Absorption Rate, Exposure Level

\section{Introduction}

In recent years, there has been an exponential growth in the use of wireless mobile communication with markets doubling roughly every two years. Much of this growth has been due to the public's increasing demand for mobile telephones, and other portable communication devices such as palmtops, mini laptops, among others. Accompanying this growth is the unavoidable increase in the number of mobile phones base station sites which generate fears in the minds of the public because of the possibly feared health impacts and safety hazards from them.

In view of the above, a comparative study of radio frequencies field levels from deployed base stations by service providers viz: MTN, GLOBACOM and AIRTEL in
Benson Idahosa University(BIU)and its environs, Benin City is being assessed in this study. The research is aimed at determining the Specific absorption rate for the general public in the far field of some deployed mobile phone Base stations for the various service providers.

The result of the study can serve as a baseline from which future survey of radio frequency (RF) radiation level in the areas elected for the study because to the best of the knowledge of the researcher, there had not been such study in the area. It will also contribute to the existing body relating to exposure to RF radiation level effects.

\subsection{Literaure Review on Electromagnetic RadiationFrom Base Station}

Mobile phone base stations, also known as base 
transceiver stations (BTS), or node B (in 3G Networks) are radio transmitters mounted on either free-standing mask or on buildings. The BTS is responsible to transmit and receive the Radio Frequency (RF) signals to the user terminal (cell phone, PDA, modem, etc). In GSMS, the BTS's are controlled by a BSC (Base Station Controller) that is connected to the MSC/VLR (Mobile Switching Center/Visitor Location Register). Radio signals are fed through cables to the antennas and then lunched as radio waves into the areas or cell around the base station. Mobile phones and their base stations are two way radios, they produce RF radiation to communicate and therefore expose the people near them to RF radiation. At some position where people are exposed to the radio waves from BTS, the level of exposure is more constant over whole body than when they are exposed to a mobile phone. Moreover, Though there no concrete evidence of health damage related to RF form BTS, but internationally acknowledged experts in the field of RF research have shown that RF (of certain range) of the type used in digital cellular antennas and phones can have critical effects on cell structures. Studies (for example, [1] and [2]) suggest a positive correlation between long-term exposure to the electromagnetic fields produced by base stations and certain types of cancer. In a cell tower radiation levels study carried out inside residential areas in Kirkuk-Iraq by Sabah (2013) [3], it was found that the radiation levels were above the recommended values. Santini et al (2002) [4]in their study observed that the people living in the vicinity of mobile phone base stations had the highest incidences of the following disorders: fatigue, sleep disturbances, headaches, feeling of discomfort, and difficulty in concentrating, depression, memory loss, visual disruptions, irritability, hearing disruptions, skin problems, cardiovascular disorders, and dizziness. Also, it has been found in different studies that RF can double the rate of lymphoma in mice, changes in and increase in tumor growth in rats, cancer in police soldiers exposed to RF and increased breaks in double and single stranded DNA (Genetic material). RF has also caused leukemia in children, headache, Neurological changes, loss of memory, increased blood pressure and damage to eye cells when combined with commonly used glaucoma medications.

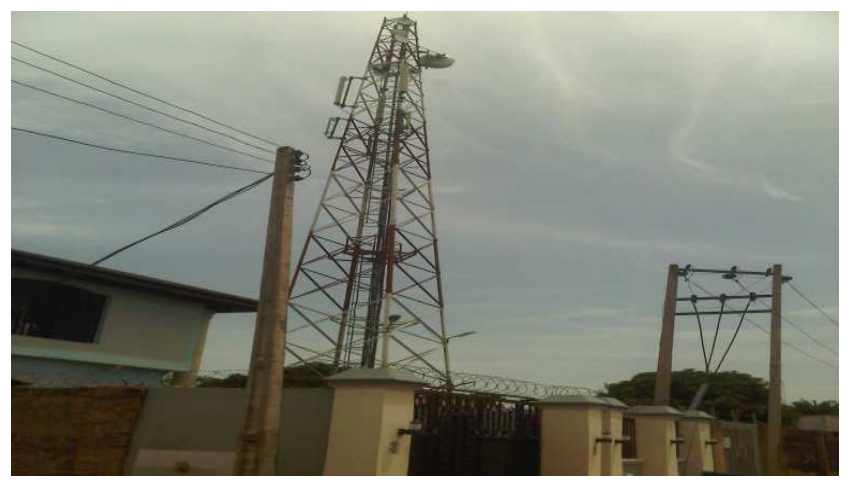

Figure 1. a. A Snap Shot of Assessed base station site at Alyanyo street.

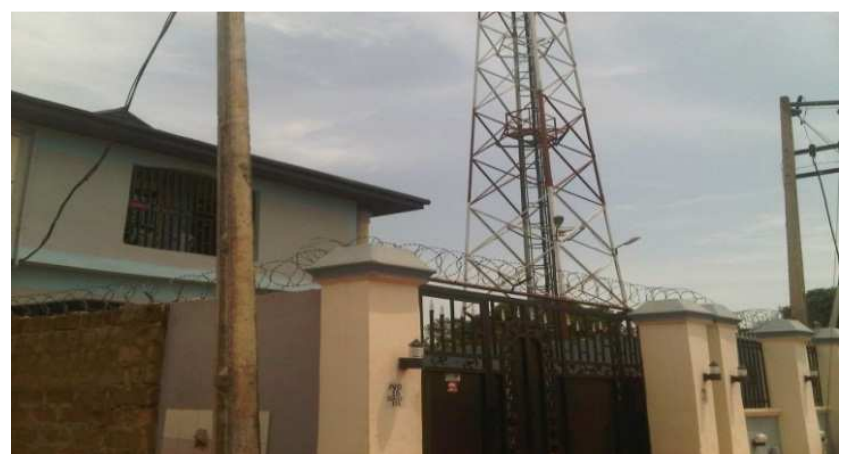

Figure 1. b. A snap shot of assessed base station site at $1^{\text {st }}$ Ugbor.

\subsection{Materials and Method}

SARs are generally estimated from numerical simulation [5] and experimental evaluation based on the E-field and thermal measurement [6-9].

In this paper, we employ the experimental evaluation based on the E-field measurement, since this method can provide the most accurate assessment of the SAR distribution.

\subsection{Measurement Approach}

One to three each of MTN, Airtel and GLO base stations were randomly selected for the study in BIU and environs, Benin. The study sites and the various locations of study are shown in table 1. Using an electromagnetic field tester (Model: EMF 827,Extech, see figure 2), a fiber measuring tape and global positioning system (GPS), electric field strength measurements were carried out up to $100 \mathrm{~m}$ from each base station antenna at intervals of 5 meters. The meter is a broad band device for monitoring high frequency radiation in range of $50 \mathrm{MHz}$ to

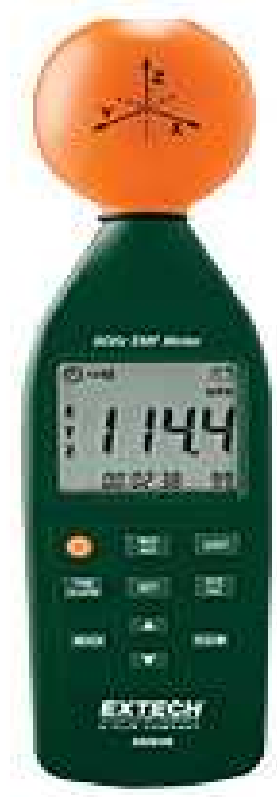

Figure 2. Extech RF/EMF strength meter.

3.6GHz. It is used in three axis (isotropic) measurement mode and five digits LCD display offers $\mathrm{mV} / \mathrm{m}, \mathrm{V} / \mathrm{m}, \mu \mathrm{A} / \mathrm{m}$, 
$\mathrm{mA} / \mathrm{m}, \mathrm{A} / \mathrm{m}, \mu \mathrm{W} / \mathrm{m} 2, \mathrm{~mW} / \mathrm{m}$ and $\mu \mathrm{W} / \mathrm{cm}$. The electric field measurements are given in $\mathrm{mW} / \mathrm{m}^{2}$. The sensor was positioned in both the vertical and horizontal directions, and the values of Electric field strength $(\mathrm{E})$ were recorded. The mean values at each of the distances were determined. Each reading was allowed to stabilize for 2 to 3 minutes before recording. These values were used to estimate SAR using equation (1).

Table 1. Network operator and Locations.

\begin{tabular}{|c|c|c|c|c|}
\hline Base station Site & Location & Longitude & Latitude & Network Operator \\
\hline 1 & BIU Campus & N60 17.063 & E005 36.160 & GLO \\
\hline 2 & Abuja quarters & N06 17.165 & E005 36.096 & MTN \\
\hline 3 & $1^{\text {st }}$ Ugbor & Long: N06 17.037 & E005 36.528 & GLO \\
\hline 5 & Ugbor parliament & N06 18.064' & E005 36.764' & GLO \\
\hline 6 & Alyanyo street & N06 18.041 & E005 36.435 & GLO \\
\hline 7 & Reuben Agho Street & Long: N06 18.092 & E005 36.183 & MTN \\
\hline
\end{tabular}

\section{SAR Evaluation and Standards}

Specific absorption rate (SAR) is the basic parameter that institutions take into consideration for the evaluation of the exposure hazards in the RF and microwave range. "Specific" refers to the normalization to mass, and "absorption rate" refers to the rate of energy absorbed by the object. "Most radiofrequency $(\mathrm{RF})$ field standards are based on the premise that there exists a threshold SAR of RF energy (for frequencies above about $1 \mathrm{MHz}$ ) of $1-4 \mathrm{~W} / \mathrm{kg}$, above which there is increasing likelihood of adverse health effects. Another method to find SAR distribution is by deriving it from Maxwell's equations. $\mathrm{E}$ and $\mathrm{H}$ are first determined analytically or numerically from Maxwell's equations. The distribution of the local SAR (W/ kg) values can be calculated directly from the electric field distribution, by the following equation [11]-[13]:

$$
S A R=\frac{\sigma|\mathrm{E}|^{2}}{\rho}
$$

Where $\sigma(\mathrm{S} / \mathrm{m})$ is the electrical conductivity, $\mathrm{E}$ is the RMS value of the electrical field strength vector $(\mathrm{V} / \mathrm{m})$, and $\rho$ is mass density of the medium $\left(\mathrm{kg} / \mathrm{m}^{3}\right)$. Using the electric fields, the dissipated power density, $P$ in any tissue can also be calculated using the following equation

$$
P=\sigma|\mathrm{E}|^{2}=\rho S A R
$$

This also implies that:

$$
S A R=\frac{\sigma|\mathrm{E}|^{2}}{\rho}=\frac{P}{\rho}
$$

Equation (1) is a point relation, so it is often called the local SAR. The space-average SAR for a body or a part of the body is obtained by calculating the local SAR at each point in the body and averaging over the part of the body being considered.

Table 2. Summary of ICNRIP's general public safety guidelines for limiting radiation exposure and SAR.

\begin{tabular}{llllll}
\hline Frequency & E-Field $(\mathbf{V} / \mathbf{m})$ & H-Field (A/m) & Power density $\left(\mathbf{W} / \mathbf{m}^{2}\right)$ & Whole body SAR(W/kg) & $\begin{array}{l}\text { Localized } \\
(\mathbf{h e a d})(\mathbf{W} / \mathbf{k g})\end{array}$ \\
\hline $400-2000 \mathrm{MHz}$ & $1.375 \mathrm{f}^{1 / 2}$ & $0.003 \mathrm{f}^{1 / 2}$ & $\mathrm{f} / 200$ & 0.08 & 2 \\
$2-300 \mathrm{GHz}$ & 61 & 0.16 & 10 & 0.08 & 2 \\
\hline
\end{tabular}

The conductivity and mass density value for the brain and the skin can be obtained from Federal Communications

\begin{tabular}{|c|c|c|c|c|c|}
\hline Material & $\begin{array}{l}900 \mathrm{MHz} \\
\varepsilon\end{array}$ & $\begin{array}{l}900 \mathrm{MHz} \\
\sigma\end{array}$ & $\begin{array}{l}1800 \mathrm{MHz} \\
\mathcal{E}\end{array}$ & $\begin{array}{l}1800 \mathrm{MHz} \\
\sigma\end{array}$ & Mass Density $\rho\left(\mathrm{Kg} / \mathrm{m}^{3}\right)$ \\
\hline Skin & 39.9 & 0.7 & 38.2 & 0.9 & 1080 \\
\hline Brain & 12.5 & 0.17 & 12.0 & 0.29 & 1180 \\
\hline
\end{tabular}

Commission (FCC) (2006) and are summarized in Table 3.

Table 3. Human Skin and Brain tissue dielectric parameters.

\section{Results and Analysis}

SAR gives a better RF radiation level estimation metric than the direct electric field strength or power density measurement. Hence, the SAR values for the present study were calculated using equation (1) for the skin and brain.
Shown in figures 3- 10 are the variations of SAR with distance for all the 8 base station sites use for the study. Summarized in table 4 are the maximum and minimum SAR values for specific site comparison. As can be seen in this table 4, the highest radiation levels were observed at a distance of $15 \mathrm{~m}, 35 \mathrm{~m}, 20 \mathrm{~m}, 35 \mathrm{~m}, 15 \mathrm{~m}, 30 \mathrm{~m}, 70 \mathrm{~m}$ and $40 \mathrm{~m}$ in sites 1-8 respectively and the SAR values in $\mathrm{W} / \mathrm{Kg}$ ranged 
from 0.00011-0.0012, which are quite lower than the maximum safety standard limit $(0.08 \mathrm{~W} / \mathrm{Kg}$ for whole body exposure and $2 \mathrm{~W} / \mathrm{Kg}$ for localized head exposure) set by the International Commission on Non-ionizing Radiation protection (ICNIRP) and other regulatory agencies.

We also observed that the SAR intensity of the radio waves fluctuates and decreases very quickly as the distance between the base station and mobile stations increases. The fluctuations may be presumably due to differences in physical parameters, (e.g. input power of the base station), in measurement protocol, (e.g. position of the measurement antenna in relation to the base station antenna and its main lobe), and in the type and characteristics of the measurement site (e.g. Side lobe effects, attenuation and obstacles like buildings, trees, ground reflections etc).

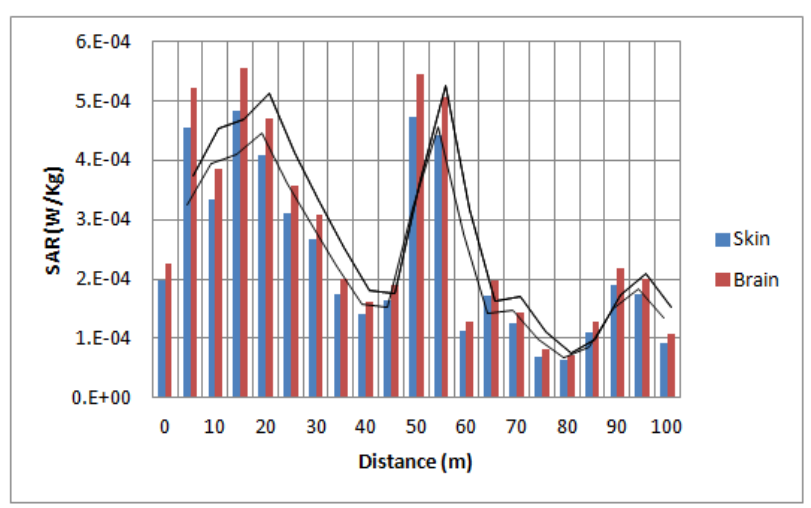

Figure 3. SAR versus distance, Base station site 1.

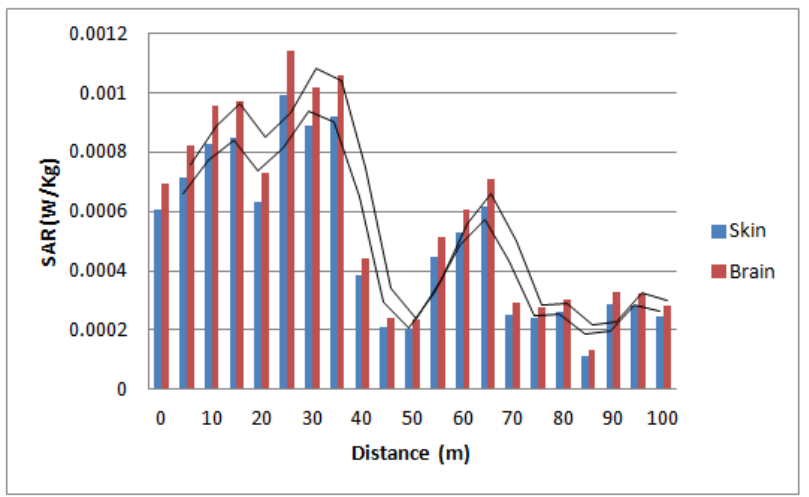

Figure 4. SAR versus distance, Base station site 2.

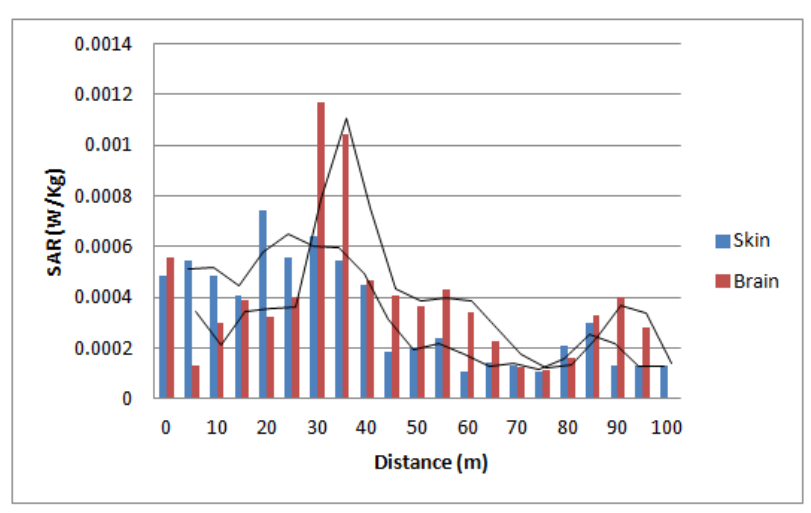

Figure 5. SAR versus distance, Base station site 3.

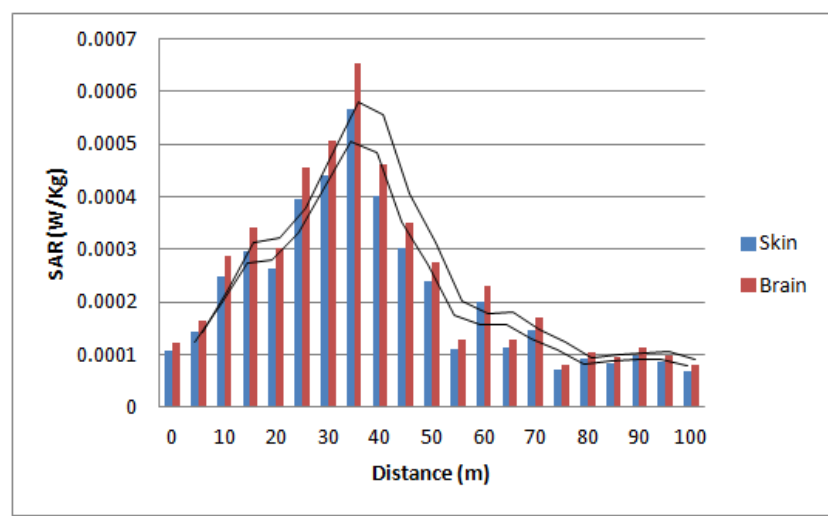

Figure 6. SAR versus distance, Base station site 4.

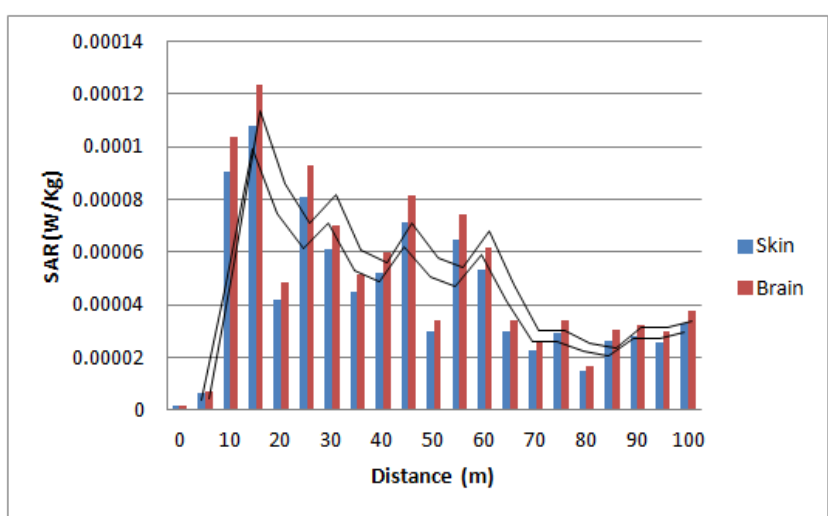

Figure 7. SAR versus distance, Base station site 5.

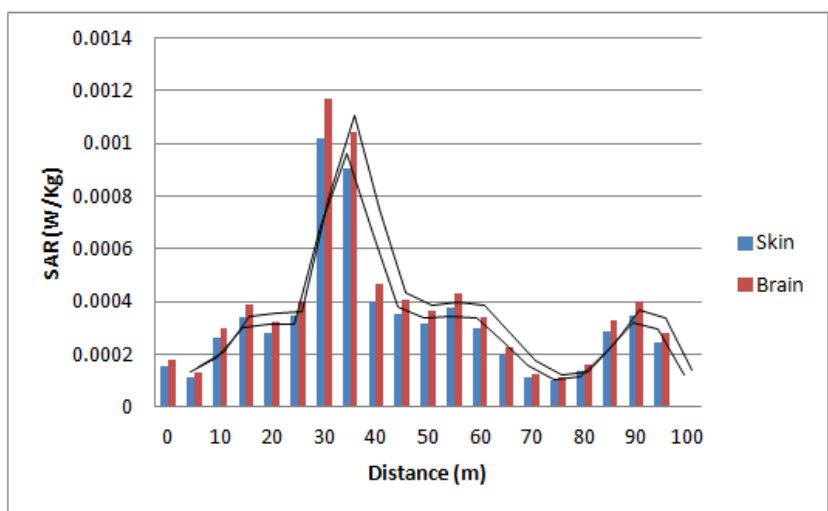

Figure 8. SAR versus distance, Base station site 6.

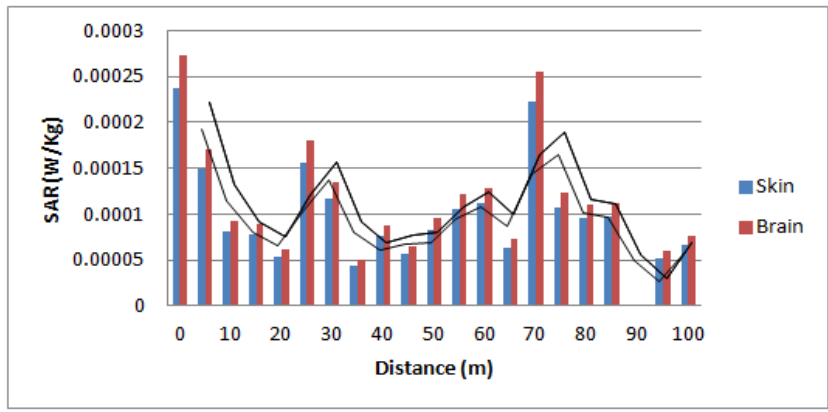

Figure 9. SAR versus distance, Base station site 7. 


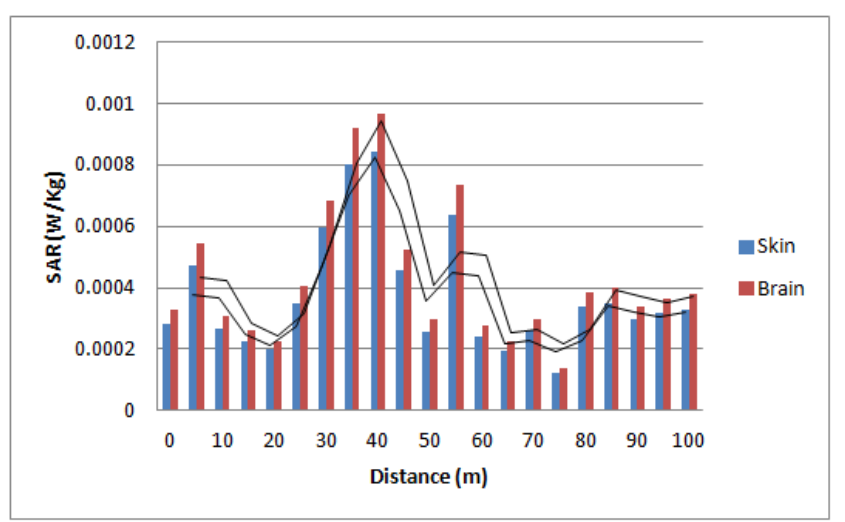

Figure 10. SAR versus distance, Base station site 8.

Table 4. Summary of Maximum SAR in skin and brain.

\begin{tabular}{lll}
\hline $\begin{array}{l}\text { Base station } \\
\text { Site }\end{array}$ & $\begin{array}{l}\text { Maximum SAR } \\
\text { (W/Kg) in Skin }\end{array}$ & $\begin{array}{l}\text { Maximum SAR in } \\
\text { (W/Kg) Brain }\end{array}$ \\
\hline 1 & 0.00048 & 0.00056 \\
2 & 0.00054 & 0.00010 \\
3 & 0.00074 & 0.00033 \\
4 & 0.00057 & 0.00065 \\
5 & 0.00011 & 0.00012 \\
6 & 0.0010 & 0.0012 \\
7 & 0.00022 & 0.00026 \\
8 & 0.00084 & 0.00097 \\
\hline
\end{tabular}

\section{Conclusions}

The electromagnetic radiation emitted by mobile phone base stations was measured in terms of electric field strength as a function of distance. The measurements were done in 8 base stations belong to four different GSM network operators in the study locations. The measured values were used to calculate specific absorption rate of the skin and brain tissue to assess the health risks. Certain directions were found to be safer than the other directions. Results shows that the values of the SAR for the eighth base stations selected for the study are within the range of $0.00010 \mathrm{~W} / \mathrm{Kg}-0.0012 \mathrm{~W} / \mathrm{Kg}$. These values are quite lower than the limit by International Commission on Non -ionizing Radiation Protection (ICNIRP) which is $0.08 \mathrm{~W} / \mathrm{Kg}$ for the whole body average SAR. This shows that there is no significant health risk for the general public that are always the vicinity of the Far field of the selected base stations for the various mobile service provider the area.

\section{References}

[1] Fesenko, E.E., Makar, V.R., Novoselova, E.G., Sadovnikov, V.B. (1999), "Microwaves andcellular immunity: Effect of whole body microwave irradiation on tumor necrosis factorproduction in mouse cells". Bioelectrochemical Bioenerg, 49(1):29-35.
[2] Krause, C.M., Sillanmaki, L., Koivisto, M., Haggqvist, A., Saarela, C., Revonsuo, A., Laine, M.and Hamalainen H., (2000), "Effects of electromagnetic field emitted by cellular phones on theEEG during a memory task", Neuroreport, 11(4): 761-764.

[3] Sabah H.S. (2013). Study of the Cell Towers Radiation Levels in Residential Areas, Proceedings of the 2013 International Conference on Electronics and Communication Systems

[4] Santini R, Santini P, Danze JM, Le Ruz P, \& Seigne M, (2002). Study of the health of peopleliving in the vicinity of mobile phone base stations: Incidence according to distance and sex,Pathology Biology, 50(6), 369-73, 200227

[5] H. Kawai, and K.Ito, "Simple Evaluation method of estimating local average SAR", IEEE Transactions onMicrowave Theory and Techniques, 52, (8), August 2004, pp.2021-2029.

[6] ICNIRP, "Guidelines for limiting exposure to time varying electric, magnetic, and electromagnetic fields(up to 300 GHz)”,Health Phys., 74, (4), April 1998, pp.494-522.

[7] O. P Gandhi, G. Lazzi, and C. M. Furse, "Electromagnetic absorption in the human head and neck for mobile telephones at 835 and $1900 \mathrm{MHz}$, IEEE Trans. Microwave Theory Tech., 44,Oct.1996, pp. 1884-1897.

[8] Y.Okano, K. Ito, I. Ida,and M. Takahashi, "The SAR evaluation method by a combination of thermographic experiments and biological tissue-equivalentphantoms", IEEE Tran. MTT, 48, (11), Nov. 2000, pp.2094-2103.

[9] N. Kuster, and Q. Balzano, "Energy absorption mechanism by biological bodies in the near field ofdipole antenna above 300 MHz”, IEEE. Transaction on Vechicular Technology., 41, (1), Feb.1992, pp.17-23.

[10] Ghandi., (1990), Biological Effects and Medical Applications of Electromagnetic Energy. Prentice Hall, Englewood Cliffs: NJ.

[11] Guy A.W. and Chow C.K.(1986), Specific Absorption Rates of Energy in ManModels Exposed to Cellular UHF-mobileantenna Fields,IEEE Trans on Microwave. Theory and Techniques, vol: MTT-34.

[12] Jagbir K and A.K. Dhami (2012). Orientation studies of a cellphone mast to assess electromagnetic radiationexposure level, International Journal of Environmental in Sciences, Vol. 2, No 3, pp 2285-2295. 